\title{
Research on Variation of Logistics Service Capability of Airport Economic Zone
}

\author{
Qian Sun 1,a , Mingfei Liu ${ }^{1, b}$, Baojia Xue 1,c \\ ${ }^{1}$ School of Management, Wuhan University of Technology, Wuhan, P.R.China, 430070 \\ a sq99110821@163.com, b liumingfei5223@163.com, c1635831276@qq.com
}

\begin{abstract}
Keywords: Airport Economic Zone, Logistics service capability, Variation, Evaluation
Abstract. The Logistics industry, one of the pillar industries of the airport economic zone, plays a key role in driving the development of regional economy. This paper selects 18 airport economic zones as the sample, based on the analysis of the influence factors of the logistics service capability, constructed the evaluation index system from the two dimensions: environmental sustaining capability and internal development capability. Using SPSS20.0 as an analytical tool, the principal component analysis was used to evaluate the correlation. It is concluded that the development level of logistics service capability is very different, and different development strategies need to be formulated. Then, using cluster analysis method, the 18 airport economic zones were divided into 5 categories. According to the different characteristics of each category, the paper puts forward some suggestions to improve the logistics service level.
\end{abstract}

\section{Introduction}

With the continuous development of large domestic airports, the concept of airport economic zone has received more and more attention, many regions have said to vigorously develop it. The State Council Development Research Center points out that the airport economic zone is formed after the economic has developed to a certain extent, based on the radiation force and influence of large airports, especially the large international hub airports. Using the advantages and facilities of air transport, logistics industry has become a part of the industrial cluster, and an important part of the entire airport economic development. And at the same time, it promotes the growth of foreign trade and economic development.

With the expansion of the global procurement, sales network has also expanded, the hope to speed up the turnover rate, and reduce the inventory, puts forward higher requirements for the logistics service capability of the Air-transportation Related Economic Zone. About the relevant research: In order to analyze and evaluate the service ability of the third party logistics enterprise, Shan Fubin (2011) has combined the grey evaluation method with analytic hierarchy process to construct grey hierarchy evaluation model [1]; Shi Xuegang (2014) has used the interpretation structure model to analyze the development strategy of aviation logistics industry of the airport economic zone [2]; Feng Shemiao (2015) has analyzed the reasons of the formation of aviation logistics type Airport Economic Zone, pointed out that the airport was the bottleneck of aviation logistics service chain [3]. At present, there is no consistent conclusion of the construction of evaluation index system of logistics service, the related research about the logistics of airport economic zone is few. At the same time, most of the domestic airport economic zone is still in its infancy, has not yet formed a complete logistics operation network, its logistics service capabilities are very different. According to the different level of logistics service capability, choosing the appropriate logistics development mode is of great significance to the development of the entire airport economy.

\section{The construction of evaluation index system}

Morash used the empirical analysis method to study the logistics service capability, and divided it into 8 kinds of ability: product delivery speed, delivery reliability, pre-sales service, after-sale service, the impact on the target market, the coverage area of the distribution network, the selectivity of 
distribution network, and distribution costs [4]. Wang Yuefeng, Liu Wei (2006) defined the regional logistics capability, and pointed out that it was the support capability and service capability, which the relevant departments provided to support its economic development [5]; On the basis of the research of the definition and elements of supply chain service capability, Ma Lijuan (2012) constructed the evaluation system of service capability [6].

From the point of the supply chain, combining the characteristics of logistics industry, which is one of the pillar industries of the airport economic zone, the service capability will be affected by the internal and external environmental conditions. On the one hand, it will be affected by the airport operation scale, logistics industry scale, structure, facilities and other internal factors; on the other hand, the condition of economic foundation, the proportion of investment, trade, information technology environment will also indirectly affect the service ability. Thus, the evaluation of logistics service capability of the airport economic zone can start from two aspects: environmental sustaining capability and internal development capability. Based on the principle of index selection, 17 indexes which can reflect the logistics service capability of the airport economic zone are selected.

Environmental sustaining capability:

Second industry added value $\left(\mathrm{X}_{1}\right)$ 、Third industry added value $\left(\mathrm{X}_{2}\right)$ 、 Social fixed assets investment $\left(X_{3}\right)$ 、Total retail sales of social consumer goods $\left(X_{4}\right)$ 、Internet broadband subscribers $\left(\mathrm{X}_{5}\right)$ 、 school enrollments of regular college $\left(\mathrm{X}_{6}\right)$ 、 post and telecommunications business volume $\left(\mathrm{X}_{7}\right)$;

Internal development capability:

permanent resident population $\left(X_{8}\right)$ 、 turnover of freight traffic $\left(X_{9}\right)$, total export-import volume

$\left(\mathrm{X}_{10}\right)$ 、 urban per capita disposable income $\left(\mathrm{X}_{11}\right)$ 、 tertiary industry's proportion $\left(\mathrm{X}_{12}\right)$ 、Total passenger traffic $\left(\mathrm{X}_{13}\right)$ 、 freight amount $\left(\mathrm{X}_{14}\right)$ 、Airport Passenger Throughput $\left(\mathrm{X}_{15}\right)$ 、Airport cargo throughput $\left(\mathrm{X}_{16}\right) 、 \mathrm{GDP}\left(\mathrm{X}_{17}\right)$ 。

\section{Logistics service capability evaluation based on principal component analysis}

\section{Data sources}

The subject investigated of this paper is the airport economic zone in Xiamen, Hefei, Shenzhen, Chongqing, Nanjing, Zhengzhou, Qingdao, Nanning, Chengdu, Tianjin, Wuhan, Nanchang, Guiyang, Changsha, Shenyang, Xian, Hangzhou and Haikou, the data mainly come from the statistical yearbook and the government websites of the 18 regions. In order to improve the reliability of the results, the data is converted into proper dimensions before the relevant analysis.

The hierarchical evaluation

Using SPSS20.0 to carry out KOM test and Bartlett's test on 7 indexes of environmental sustaining capability. As shown in table 1.

Table 1 KOM test and Bartlett's test

$\begin{array}{lcl}\text { Kaiser-Meyer-Olkin metrics for sampling sufficiency } & .726 \\ \text { Bartlett's test of Sphericity } & \text { Approx. Chi-Square } & 122.733 \\ & \mathrm{df} & 21 \\ & \text { Sig. } & .000\end{array}$

Table 2 Principal component extraction table of environmental sustaining capability

\begin{tabular}{clccccc}
\hline Component & \multicolumn{3}{c}{ Initial Eigenvalues } & \multicolumn{3}{c}{ Extraction Sums of Squared Loadings } \\
\cline { 2 - 6 } & total & \% of Variance & Cumulative \% & Total & \% of Variance & Cumulative \% \\
1 & 4.822 & 68.884 & 68.884 & 4.822 & 68.884 & 68.884 \\
2 & 1.173 & 16.764 & 85.647 & 1.173 & 16.764 & 85.647 \\
3 & .447 & 6.390 & 92.037 & & & \\
4 & .281 & 4.017 & 96.055 & & & \\
5 & .160 & 2.291 & 98.346 & & \\
6 & .104 & 1.486 & 99.831 & & & \\
7 & .012 & .169 & 100.000 & & & \\
\hline
\end{tabular}


As can be seen from table 2, the eigenvalues of the first 2 principal components are greater than 1 , and the cumulative contribution rate is up to $85.646 \%$, so the former F1 and F2 are the main components. The factor loading matrix for calculating the maximum variance orthogonal rotation is calculated. The results are shown in table 3.

Table 3 Rotated Component Matrix (environmental sustaining capability)

\begin{tabular}{lll}
\hline & \multicolumn{2}{c}{ Component } \\
\cline { 2 - 3 } $\mathrm{X}_{1}$ & 1 & 2 \\
$\mathrm{X}_{2}$ & .907 & -.243 \\
$\mathrm{X}_{3}$ & .943 & .072 \\
$\mathrm{X}_{4}$ & .937 & -.097 \\
$\mathrm{X}_{5}$ & .935 & .085 \\
$\mathrm{X}_{6}$ & .820 & .381 \\
$\mathrm{X}_{7}$ & -.032 & .973 \\
\hline
\end{tabular}

After calculating the coefficient of each index, we can get the formula for calculating the score of each principal component:

$$
\begin{aligned}
& F_{1}=0.191 X_{1}+0.195 X_{2}+0.196 X_{3}+0.193 X_{4}+0.166 X_{5}-0.190 X_{6}+0.172 X_{7} \\
& F_{2}=-0.219 X_{1}+0.050 X_{2}-0.094 X_{3}+0.060 X_{4}+0.314 X_{5}+0.829 X_{6}-0.057 X_{7}
\end{aligned}
$$

According to the weighted contribution of the variance contribution rate of each principal component to the variance contribution rate of all principal components, we can get the evaluation formula of environmental sustaining capability.

$\mathrm{A}_{1}=0.804 \mathrm{~F}_{1}+0.196 \mathrm{~F}_{2}$

The principal component score of each region can be calculated and results are shown in table 4 .

Table 4 Principal component score of environmental sustaining capability.

\begin{tabular}{llll}
\hline Subject & $\mathrm{A}_{1}$ & Subject & $\mathrm{A}_{1}$ \\
\hline Xiamen & -0.467 & Tianjin & 1.649 \\
Hefei & -0.430 & Wuhan & -0.167 \\
Shenzhen & 0.907 & Changsha & -0.538 \\
Chongqing & 1.639 & Nanchang & -0.823 \\
Nanjing & 0.236 & Guiyang & $-1,073$ \\
Zhengzhou & -0.471 & Shenyang & -0.147 \\
Qingdao & -0.410 & Xian & 0.828 \\
Nanning & -0.747 & Hangzhou & 0.209 \\
Chengdu & 0.647 & Haikou & -0.822 \\
\hline
\end{tabular}

By using the above methods, the internal development capability of the airport economic zone is evaluated. The KOM test and Bartlett's test are carried out, the KMO value is 0.586 , and the spherical Bartlett test has a significant probability of less than 0.05 . Factor analysis is used to extract the first 2 factors F3 and F4 as the main components, and the formula of each principal component score is obtained:

$$
\begin{aligned}
& \mathrm{F}_{3}=0.199 \mathrm{X}_{8}+0.193 \mathrm{X}_{9}+0.187 \mathrm{X}_{10}-0.079 \mathrm{X}_{11}+0.034 \mathrm{X}_{12}+0.164 \mathrm{X}_{13}+0.199 \mathrm{X}_{14}+0.124 \mathrm{X}_{15}-0.086 \mathrm{X}_{16}+0 . \\
& 113 \mathrm{X}_{17} \\
& \mathrm{~F}_{4}=-0.040 \mathrm{X}_{8}+0.093 \mathrm{X}_{9}+0.128 \mathrm{X}_{10}+0.308 \mathrm{X}_{11}+0.416 \mathrm{X}_{12}-0.107 \mathrm{X}_{13}+0.018 \mathrm{X}_{14}+0.011 \mathrm{X}_{15}+0.114 \mathrm{X}_{16}+ \\
& 0.470 \mathrm{X}_{17}
\end{aligned}
$$

According to the weighted contribution of the variance contribution rate of each principal component to the variance contribution rate of all principal components, we can get the evaluation formula of internal development capability:

$$
\mathrm{A}_{2}=0.709 \mathrm{~F}_{3}+0.291 \mathrm{~F}_{4}
$$

Then the principal component score of each region can be calculated.

After calculating the scores of two dimensions of logistics service capability, the ratio of the variance of each stratification ability score to the total variance is taken as the weight. The weight of environmental sustaining capability is 0.415 , the weight of internal development capability is 0.585 , and weighted to calculate the comprehensive score, as shown in table 5. 
Table 5 The principal component score of logistics development capability

\begin{tabular}{lclc}
\hline Subject & Composite score & Subject & Composite score \\
\hline Xiamen & -0.275 & Tianjin & 1.437 \\
Hefei & -0.673 & Wuhan & 0.310 \\
Shenzhen & 0.428 & Changsha & -0.453 \\
Chongqing & 1.664 & Nanchang & -0.629 \\
Nanjing & 0.137 & Guiyang & -1.064 \\
Zhengzhou & 0.123 & Shenyang & -0.142 \\
Qingdao & -0.372 & Xian & 0.951 \\
Nanning & -0.720 & Hangzhou & -0.115 \\
Chengdu & 0.226 & Haikou & -0.821 \\
\hline
\end{tabular}

From table 5, the logistics service ability from high to low is: Chongqing, Tianjin, Xian, Shenzhen, Wuhan, Chengdu, Nanjing, Zhengzhou, Hangzhou, Shenyang, Xiamen, Qingdao, Nanchang, Hefei, Changsha, Nanning, Haikou, Guiyang.

\section{Difference evaluations}

In order to compare the logistics service level of the selected 18 airport economic zones, to understand the differences, the cluster analysis of is used to obtain the regional distribution, as shown in table 6 .

Table 6 Regional differences of logistics service capability

\begin{tabular}{lccc}
\hline Strength & clustering & Amount & Subject \\
\hline The Strongest & I & 3 & Chongqing、Tianjin、Xian \\
Stronger & II & 5 & $\begin{array}{c}\text { Shenzhen、Wuhan、Chengdu、 } \\
\text { Nanjing、Zhengzhou }\end{array}$ \\
General & III & 3 & Hangzhou、Shenyang、Xiamen \\
Weaker & IV & 4 & Qingdao、Changsha Nanchang、Hefei \\
The weakest & V & 3 & Haining、Haikou、Guiyang
\end{tabular}

From table 6, the logistics service ability from strong to weak can be divided into 5 categories, the logistics service ability of class I and II is Strong, including Chongqing, Tianjin, Xian, Shenzhen, Wuhan, Chengdu, Nanjing, Zhengzhou; Logistics service ability of class III is general, including Hangzhou, Shenyang, Xiamen; Logistics service ability of class IV and V is poor, including Qingdao, Nanchang, Hefei, Changsha, Nanning, Haikou, Guiyang. According to the different characteristics, we can put forward the following suggestions:

The class I and II: Logistics service capability is the strongest, but there are also some differences. Chongqing Airport Economic Zone is in the first place, airport economic zones in this category can pay more attention to the logistics of information technology, based on the national transportation logistics public information platform, integrating all kinds of basic and special information of government, enterprise and society, vigorously carrying out the construction of data exchange between major related industries node. To encourage logistics enterprises to strengthen the development and application of advanced information technology, and accelerate the development of modern logistics industry. At the same time, to speed up the construction of public service facilities, the formation of a good ecological environment.

The class III: Logistics service capacity is at a moderate level, and needs further improvement. At this stage of the airport economic zone, it is recommended to fully understand the advantages of them, to determine the logistics industry development model. At the same time, to attach more importance to multimodal transport facilities. To form a fast and convenient logistics channel, and promote the further development of airport logistics.

The class IV and V: Logistics service capability is weak, they need to guide the development of Airport Economic Zone under the guidance of relevant policies. It is recommended to attache great importance to the airport as the center, vigorously introducing domestic and foreign airlines and 
logistics giants, and actively building a strong route network system, improving the accessibility of the airport, and accelerating the improvement of other supporting facilities. At the same time, playing the leading role of the government, jointly promoting the construction of the logistics industry in the airport economic zone.

\section{Conclusions}

The development of Airport Economic Zone in China is becoming more and more prosperous. The logistics industry is one of the pillar industries, and the capability of logistics service plays an important role in the development of the whole economic zone. Therefore, it is very important to evaluate the level of logistics service capability of airport economic zone. This paper constructs the evaluation system of airport economic zone logistics service capability, uses principal component analysis method to evaluate logistics service capacity of 18 airport economic zones, and uses hierarchical clustering analysis to evaluating the each region, then puts forward some suggestions: each airport economic zone needs to develop different strategies according to the different characteristics of logistics development, which have a certain theoretical and practical significance. The research also has some shortcomings: The design of the evaluation index system of logistics service capability, is based on the situation of domestic airport economy zone, which lacks the general applicability; On the basis of the full reading of the literature, referring to other related research, but there are still some subjectivity in the specific operation. In the future research, we will use more methods to validate the model and make the model more accurate.

\section{Acknowledgements}

This work was financially supported by the Logistics Industry Planning Project of Wuhan Airport Economic Zone.

\section{References}

[1] Shan Fubin. Evaluation of the Third-Party Logistics Enterprise' Service Capability Based-on Grey Hierarchy Method [J]. Journal of Langfang Teachers University(Natural Science Edition), 2011, 11(4):77-80. (In Chinese)

[2] Shi Xuegang, Miaotianfeng. Analysis of Influence Factors of Development of Aviation Logistics Industry in Near-port Economic Zones[J]. Logistics Technology, 2014(21):221-223. (In Chinese)

[3] Feng Shemiao. Study on Formation Mechanism of Aviation Logistics in Airport Economic Zone [J]. Port Economy, 2015(2):35-37. (In Chinese)

[4] Edward A.Morash,Comelia L.M.Droge, Shawnee K.Vickery. Strategic Logistics Capabilities for Competitive Advantage and Firm Success[J]. Journal of Business Logistics, 1996, 17(1): pp.47-69.

[5] Wang Yuefeng, Liuwei. Consideration on Some Problems of Area Logistics Capability Plan and Area Economic Development [J]. Logistics Sci-Tech, 2006, 29(11):77-79. (In Chinese)

[6] Ma Lijuan. Supply Chain Logistics Service Capability and Evaluation Analysis [J]. Modern Business Trade Industry, 2012, 24(1):26-27. (In Chinese) 